\title{
Pomelo export logistics process: modern factors of efficiency (the case of wiang kaen district, chiang rai province, Thailand)
}

\author{
Wannee Sutthachaidee ${ }^{1}$, Bavornluck Kuosuwan ${ }^{2, *}$, and Bhuk Kiranantawat ${ }^{1}$ \\ ${ }^{1}$ College of Logistics and Supply Chain, Suan Sunandha Rajabhat University, 10200, U-Thong Nok \\ rd, Dusit, Bangkok, Thailand \\ ${ }^{2}$ Panyapiwat Institute of Management, Pak Kred, Nonthaburi, Thailand
}

\begin{abstract}
The objective of this research is to study the logistics process and problems of the quality of pomelos for export in Wiang Kaen district, Chiang Rai province. Applied research methodology was used in this research. In-depth interview was conducted to collect qualitative data. Content analysis was employed to analyze data collected. From the research, it was found that Wiang Kaen Pomelo Community Enterprise for Export has the cultivation area of approximately 1,000 rai (160 ha). The logistics process of pomelos in WiangKaen district can be classified into 3 main phases which are raw materials, cultivation process and finished goods. In raw materials, the most common type of pomelo cultivated is Thongdee. In cultivation process, pomelo trees are planted from May to June. Irrigation is done through sprinklers every 10 days. Fertilizerapplication for trees aged 1-4 years is done by applying chemical fertilizer $15-15-15,300-500$ grams per tree for every 2 months, together with manure. Copper is sprayed to prevent Canker disease. In finished goods, harvesting is carried out in 3 periods. The quality of products will be graded according to weight. Top export markets of pomelos in Wiang Kaen are China, followed by the European Union countries.
\end{abstract}

\section{Introduction}

Fruit and vegetables are considered export products that generate tremendous revenue for Thailand. Annually, Thailand exports fruit and vegetables in form of fresh, chilled, frozen, and dried products valued at 3-4 billion baht. Fruit and vegetable export has an average growth rate of $15-20 \%$ per year. This is due to the variety of Thai fruit and vegetables produced and continuous production of Thai fruit and vegetables all year round [1].

As a result, it gives Thailand a competitive advantage in product variety and flexibility in export volume. In addition, Thai fruit and vegetables are quality products which have been accepted by consumers in foreign countries. As Thai government has a policy to open free trade, both in bilateral and multilateral frameworks such as ASEAN Free Trade Area

*Corresponding author: bovornluck@gmail.com 
(AFTA), Thailand-China, Thailand-Australia, Thailand-New Zealand, Thailand-Japan, ASEAN-China and ASEAN-Japan, Thailand has received numerous benefits in export. However, there will be some groups of Thai agricultural products that are affected in which the severity of the impact on each agricultural product varies according to the competitiveness of the product type. Thai exports are on the declining trend. It can be seen that the value of Thai exports of 15.1 billion US dollars, decreased by 8 percent in April 2016, which was a negative growth inthe last 2 months [2].

Pomelo is an important fruit to the economy of Thailand and is widely grown [3]. Apart from domestic consumption, there is also the potential for pomelo exports due to long shelf life and resistance to impact during long-distance transport. Pomelo exports from 2008 to 2010 were around 11,000-12,000 tons, with an approximate value of 109-129 million baht. The major markets are China, Hong Kong, Singapore and Laos [4]. Pomelos exports to European markets such as the Netherlands, Republic of Ukraine, the United Kingdom and Canada are uncertain due to limitations in marketing and phytosanitary. Currently, there is a high demand for Thai pomelos in the international market. Pomelo was also the fruit that generated the 10thhighest value export value from 2013 to 2015 [4].

Mr. Somsak Bunyuang, the former president of Wiang Kaen Pomelo Community Enterprise for Export, said that the Wiang Kaen's pomelo production strategy focuses on producing off-season pomelos. As the central and southern regions only produce pomelos in season, this results in prices of pomelos being as high as 70 baht per kilogram, which is higher than any other year. The cultivation area of pomelos has been expanded from the 2,000 rai (320 ha) to 3,700 rai (592 ha), with the yield of more than 2 million pomelos and the export of over 60 tons to EU market. In 2019, the community enterprise exported more than 100 million baht worth of pomelos.

This research aims to study the logistics process of pomelos for export in Wiang Kaen district, Chiang Rai province which will enhance the capability of pomelo exporters and increase the efficiency of the logistics process.In addition, this research will also provide crucial information which can help pomelo exporters to acquire customers in new export markets.

\section{Research Objectives}

1. To study the logistics process of pomelos for export in Wiang Kaen district, Chiang Rai province, Thailand

2. To analyze the problems of the quality of pomelos for export in Wiang Kaen district, Chiang Rai province, Thailand

\section{Research methodology}

Data used in this research was secondary data and primary data. Data was collected using qualitative method. Content analysis was conducted for data analysis. The sample was Wiang Kaen Pomelo Community Enterprise for Export, pomelo farmers in Wiang Kaen district, Chiang Rai province and agricultural development and production promotion scholars. Primary data collection was carried out by focus groups, in-depth interviews and surveys to understand the logistics process and analyze the problems of the quality of pomelos in Wiang Kaen district. 


\section{Results}

The general information of Wiang Kaen Pomelo Community Enterprise for Export can be summarized in Table 1 as follows:

Table 1. General Information of Wiang Kaen Pomelo Community Enterprise for Export

\begin{tabular}{|c|c|}
\hline 1. Year established & 2005 \\
\hline 2. Current president & Mr. ChavalitBoonthan \\
\hline 3. Number of members & 100 \\
\hline 4. Total cultivation area & $5-1000$ rai (160 ha) \\
\hline 5. Average farm size & Thes -1.6 ha) \\
\hline $\begin{array}{c}\text { 6. Number of pomelos cultivated } \\
\text { per 1 rai ( 0.16 ha) }\end{array}$ & 25 pomelo trees, aged between 1 - years \\
\hline 7. Main pomelo varieties cultivated & Thongee, Khao Yai and Zeller \\
\hline 8. Projected output & $\begin{array}{c}150-300 \text { pomelos per tree or 5-6 tons per rai } \\
(0.16 \text { ha), 5,500 tons for the whole cultivation } \\
\text { area }\end{array}$ \\
\hline
\end{tabular}

The logistics process of pomelos in Wiang Kaen can be summarized in Figure 1 as follows.

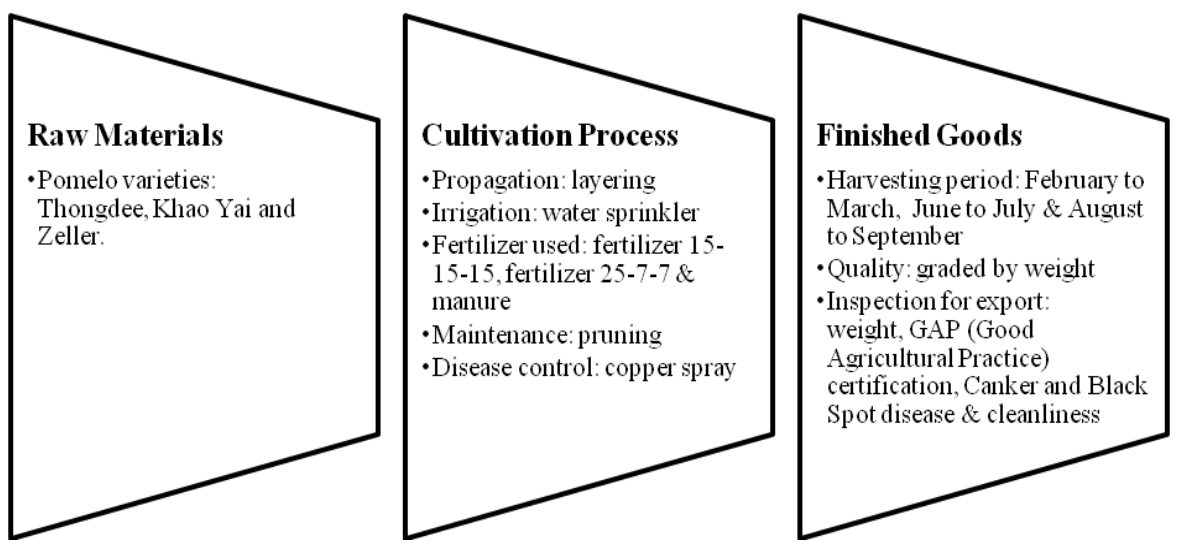

Fig. 1. Logistics Process of Pomelos in Wiang Kaen.

The logistics process of pomelos in Wiang Kaen can be classified into 3 main phases which are raw materials, cultivation process and finished goods [5].

In raw materials, the most cultivated pomelo varieties are Thongdee, followed by Khao Yai and Zeller. Propagation is done through layering. Parent trees are 6-10 years old. Seedlings are 6 months old. The soil in Wiang Kaen district is loamy which does not absorb a lot of water. The climate in the area is suitable for pomelo cultivation.

In cultivation preparation, holes in the size of $50 \times 50 \times 50 \mathrm{~cm}$ are dug and the distance between each scion planted is $8 \times 8 \mathrm{~m}$. Holes are then lined with manure, compost and hay. 25 trees can be planted in 1 rai ( 0.16 ha) of land. In cultivation process, May - June is a suitable period for cultivation. Scions are placed in the holes and the holes are covered with soil. Scions are tied to sticks to prevent bending. Irrigation is done through sprinklers every 10 days. When pomelos trees begin to grow fully, less water is given by observing the moisture of the soil. Fertilizer application for trees aged 1-4 years is done by applying chemical fertilizer 15-15-15, 300-500 grams per tree for every 2 months, together with manure. Trees will start to produce fruit when they are around 4 years old. 
For trees at this age, chemical fertilizer 13-13-21 or 15-15-15 is applied.Copper is sprayed to prevent Canker disease [6].1 kg of chemical fertilizer 8-24-24 is added per tree for 1 month. Approximately, $1 \mathrm{~kg}$ of chemical fertilizer 25-7-7 is added per tree to speed leafing and flowering.After6 months of harvesting, fertilizer needs to be reapplied to the trees. Tree maintenance and weeding is done by loosen the soil at the base of the trees regularly.

When loosening the soil, hitting the base and roots of the trees must be avoided. When chemicals are sprayed, the chemicals must not be spilled onto the leaves [7]. After harvesting is finished, care and maintenance of the trees is done by pruning. Dry, dead, broken and diseased branches, vertical-growing sucker shoots and rubbing branches are pruned. Antifungal or red limestone paste is applied to the cuts to prevent rotting due to fungal infection [8].

In finished goods, harvesting is carried out in 3 periods. The first period is from February to March. The second period is from June to July. The third period is from August to September. The quality of products will be graded according to weight. No. 1 products weight $1.20 \mathrm{~kg}$ or more. No. 2 products weight $0.80-1.20 \mathrm{~kg}$ and No. 3 products weight less than $0.80 \mathrm{~kg}$. For export, quality is inspected by weight. Moreover, GAP (Good Agricultural Practice) certification, and Canker and Black Spot disease are checked [9].

In addition, the ripening of pomelos must be at $75 \%$ or above, and the cleanliness of pomelos is inspected. Lastly, the skin of pomelo should not have more than $5 \%$ of blemishes. Top export markets of pomelos in Wiang Kaen are China, followed by the European Union countries, such as the Netherlands, the United Kingdom, Italy, Germany and France. International orders are made through an agent who acts as an intermediary.

Orders are then received by the Wiang Kaen Pomelo Community Enterprise for Export. Community members will collect products according to the amount specified in the order and select products that are of export quality. Product packaging is done at the point of sale of Wiang Kaen Pomelo Commuinty Enterprise for Export. The products for export are mostly harvested in the second and third period. Products harvested in the first period and products that do not pass the inspection for export are sold to local middlemen for the domestic market. The problem of the quality of pomelos for export in Wiang Kaen district is the sweetness of the pomelos [10]. The quality of off-season pomelos is not as good as pomelos produced in season and in terms of sweetness and taste.

\section{Discussion}

The results of the research are consistent with the research of Santhasap [11] on the development of quality pomelo production in the northern region for export which aims to develop quality pomelo production for export. Pomelo quality management is divided into two aspects. The first aspect is quality management of the appearance of pomelos on color and texture through prevention and eradication of pomelo diseases and pests.

The second aspect is the quality management of the pomelos on size and taste of pomelos through nutrient management. The results showed that the pomelo farm which is managed according to standard agricultural practices and follows the recommendations of Thailand Research Fund (TRF) produces good quality pomelos. Moreover, insect infestation occurs less than the farm using conventional agricultural methods. In cultivation process, chemical and fertilizer application also plays an important role in ensuring food safety and export quality yield [12].

The results also showed that, in terms of irrigation, sprinkler is the most adopted method in irrigation which ensures good quality yield for export [13]. In variety selection, Thongdeeis the most preferred variety. This is consistent with the research of Angyurikun 
and Thaksin-Wisut [14] on pomelo's production economics and marketing in central region.

The objective of the research is to find cost and return on production, production potential and competition, and cost-effectiveness and risk rate of investment of pomelo farmers. In marketing, the research aims to find effective marketing methods and marketing margin. From the research, in production economics, it was found that cultivating Thongdee pomelos provides a net income of 40,572.97 baht per rai ( $0.16 \mathrm{ha})$ anda good return on investment, and has very low risk.

In Thai pomelo export market, $65 \%$ of Thai pomelos are exported to China which is the largest Thai pomelo export market. Pomelo farmers in WiangKaen district have the potential to drive pomelo exports and generate more income through export to new foreign markets [15].

\section{Recommendations}

In logistics process of pomelos for export in WiangKaen district, for raw materials, pomelo variety selection is extremely crucial. The farmers primarily cultivate Thongdee which is a variety that provides quality yield in accordance with the quality standard and market demand. Moreover, there is low risk and high value in cultivating Thongdee.

Planting, irrigation, fertilizing and maintenance should be managed in accordance with the recommendations of Thailand Research Fund (TRF) in cultivation process. It will result in good quality pomelos and less insect infestation. In finished goods, pomelos harvested in the first period (February-March) generally do not meet the standard for export. Therefore, the farmers need to focus on caringfor those pomelos trees giving yield in the period from February to March, so that the yieldwill meet the export standard.

As international orders of Wiang Kaen pomelos are made through an agent who acts as an intermediary, if the community enterprise is able to directly take orders from international customers, more revenue can be generated. As Wiang Kaen pomelos are producedoff season, the quality of the pomelos is not as good as those produced in season.

Hence, there should be an agency that is able to help develop off-season pomelo production which can produce good quality pomelos [16]. In addition, pomelo processing should be developed to add value to products and help create products that are unique to Wiang Kaen.

\section{References}

1. D. Ushakov, V. Shepelev, Y. Patlasov, IOP Conf. Ser: Earth and Env. Sc. 422 (2020).

2. Statistics Report (Thai Customs Department, 2017).

3. S. Charoenpoom, K. Chanda, The EUrASEANs 3(16), 46 (2019).

4. Thailand. Agricultural Products Export Service Division (Department of Agriculture, Thailand, 2016).

5. C. Praison, Production and operation management. (Green Apple Graphic, 2013).

6. N. Kositcharoenkul, J. of Plant Pathology 19 (1-2), 35 (2005).

7. B. Manatmanong, Studies on Species, Damaged and Control of Fruit Flies in Pummelo (Dep. of Agriculture of Thailand, 2011).

8. A. Paradanuwat, J. of Horticulture 19(2), 129-135 (1984)

9. S. Likit-Ekarat, Black Spot Disease Management of Thong Dee Pomelo for Export. Department of Agriculture of Thailand (2009). 
10. J. Prasopsuk, Report on the situation of pesticide residues in vegetables and fruits in the upper northeastern region of 2012 (Ministry of Agriculture and Cooperatives, Mueang District, Thailand, 2012).

11. C. Santhasup, Development of quality pomelo production in the northern region for export (Thailand Research Fund E-Library, 2013)

12. T. Limunggura, T. Mekhora, Pomelo Production and Market Pattern of the Pomelo Quality Development Group, Samut Songkram Province, Thailand. (Int. Symposium on SocManSys, Australia, 2013).

13. K. Duangta, Y. Borisutdhi, S. Simaraks, Forest and Society 2(2), 162 (2014).

14. N. Angyurikun, S. Thaksin-Wisut, Pomelo's Production Economics and Marketing in

15. K. Apipradchayasakul, Production management (Focus Media and Publishing Company Ltd, 2014).

16. A. Lakchaikun, Report on performance and satisfaction of agriculture promotion staff in vegetable promotion project (Min. of Agriculture and Cooperatives, Thailand, 2013). 